\title{
O Estágio Supervisionado na formação do professor de Filosofia
}

\section{The Stage Supervised in the formation of the teacher of Philosophy}

\author{
Stania Nagila Vasconcelos Carneiro* \\ Elisangela André da Silva**
}

\begin{abstract}
RESUMO
Os estudos sobre a formação docente nos cursos de licenciatura têm sido objeto de estudo no campo da educação. A defesa do professor intelectual, crítico e reflexivo nem sempre tem considerado a contribuição da Filosofia na elaboração dos seus princípios. O objetivo desta pesquisa é analisar a compreensão dos alunos acerca do Estágio no decorrer do curso de licenciatura. Optou-se, metodologicamente, pela abordagem qualitativa, a revisão bibliográfica, a pesquisa de campo e a análise de conteúdo. A pesquisa de campo consultou dez estudantes de Licenciatura em Filosofia da turma de Prática de Ensino da Universidade Estadual do Ceará. O embasamento teórico para as análises dos dados ancorou-se nos estudos de Gallo (2007), Ghedin (2009), Severino (1994), Lima (2012), Pimenta e Lima (2004), dentre outros. Os resultados da pesquisa revelaram que o Estágio é um dos momentos mais significativos do curso universitário, pois possibilita ao aluno a vivência, na prática, dos ensinamentos teóricos e o contato com a realidade da profissão docente. Cada graduando tem um conceito e um significado para tal vivência, que influenciará, como passo inicial no exercício do magistério e na construção de sua identidade professoral.
\end{abstract}

Palavras-chave: Estágio. Ensino de Filosofia. Formação docente.

${ }^{*}$ Centro Universitário Católica de Quixadá. Quixadá, Ceará, Brasil. E-mail: fcrs1532@fcrs. edu.br - http://orcid.org/0000-0002-0911-5344

${ }^{* *}$ Universidade da Integração da Lusofonia Afro-brasileira. Redenção, Ceará, Brasil. E-mail: elisangelaandre@unilab.edu.br - http://orcid.org/0000-0003-0074-1637 


\begin{abstract}
Studies about teacher education in degree courses have been studied in the field of education. The teacher's defense intellectual, critical and reflective not always have considered the contribution of Philosophy in preparing its principles. The objective of this research is to analyze the students' understanding about the stage during the degree course. We opted for a qualitative approach methodologically, the literature review, field research and content analysis. The fieldwork consisted of ten students of Degree in Philosophy class of Teaching Practice at the State University of Ceará. The theoretical basis for analysis of the data was anchored in studies of Gallo (2007), Ghedin (2009), Severino (1994), Lima (2012), Pimenta and Lima (2004), among others .The survey results revealed that Stage is one of the most significant moments of the university, since it allows the student to experience, in practice the theoretical knowledge and contact with the reality of the teaching profession. Each graduate has a concept and a meaning to this experience, which will influence the practice of teaching and building your identity professorial
\end{abstract}

Keywords: Stage. Teaching Philosophy. Teacher training.

\title{
Introdução
}

A presente pesquisa trata do Estágio Curricular Supervisionado como espaço prático da formação docente que possibilita a interação entre o estagiário e a escola de atuação profissional.

As pesquisas e estudos voltados para o tema Estágio Supervisionado e Prática de Ensino desenvolvidas na área de educação estão mais localizadas no campo da Pedagogia, enquanto nas disciplinas específicas pouca produção é encontrada. O curso de Licenciatura em Filosofia, mesmo preparando professores para a educação básica, também se ressente desta preocupação, ficando, muitas vezes, o estágio restrito ao cumprimento da grade curricular. Com isto, parece estar instaurada uma "cultura" de distanciamento entre o campo da Filosofia e o da Educação.

Em relação ao interesse do tema, ele decorre da experiência em escolas de Ensino Fundamental e Médio que nos levou a perceber o quanto é enriquecedor esse contato do licenciando com o contexto concreto de exercício da profissão. Nessa direção, vemos o Estágio Supervisionado como primeiros passos para a identidade profissional, como afirma Lima (2012). Questionamos, assim, até que ponto os alunos do curso de Filosofia também percebem a necessidade de contato com a realidade escolar. Em decorrência disso surgiu a grande pergunta deste 
trabalho: qual a visão dos alunos da Licenciatura em Filosofia da Universidade Estadual do Ceará (UECE) sobre o estágio? A partir dessa indagação foram definidos os objetivos deste estudo, que é analisar a compreensão dos alunos acerca do Estágio no decorrer do curso de licenciatura, bem como realizar um percurso teórico sobre o tema.

Nosso estudo foi conduzido mediante a abordagem qualitativa de pesquisa, que, conforme Flick (2009, p. 37), “dirige-se à análise de casos concretos em suas particularidades locais e temporais, partindo das expressões e atividades das pessoas em seus contextos locais", aliada à revisão bibliográfica de autores que estudam sobre o tema em questão. Para a coleta de dados no campo, contamos com a colaboração de dez graduandos, matriculados na disciplina de Prática de Ensino em Filosofia, da Universidade Estadual do Ceará, junto aos quais investigamos, por meio da aplicação de questionário, diferentes concepções acerca do Estágio.

Esperamos que os resultados da pesquisa, aqui apresentada, nos ajudem a compreender o estágio na complexidade formativa do projeto pedagógico do curso universitário, pois possibilita ao aluno a oportunidade de práxis, a partir da vivência com a realidade da profissão docente. Cada graduando tem um conceito e um novo significado para tal vivência, o que influenciará no exercício do magistério e na construção da identidade professoral de cada sujeito. Esperamos ainda, que os estudos e pesquisas que fundamentam este trabalho conduzam a uma reflexão sobre a formação dos futuros professores de Filosofia, que atuarão nos espaços escolares.

\section{Sobre o saber filosófico e o ensino de Filosofia}

No contexto institucional das escolas, muitas vezes, a Filosofia esteve reduzida a uma fragmentação disciplinar, se distanciando da sua real função que é a busca do saber inteiro. Diante desta realidade, a Filosofia precisa ser compreendida como uma forma de pensar e atuar na sociedade, fazendo parte da formação contínua dos graduandos e podendo ser considerada uma atividade interminável na vida, no trabalho e do desenvolvimento profissional docente.

A respeito das características da Filosofia, Rios nos ensina que:

A Filosofia se caracteriza como busca amorosa de um saber inteiro. Ver com clareza, abrangência e profundidade a realidade, assumindo diante dela uma atitude crítica, é a tarefa constante do filósofo, que além do 
mais, orienta-se num esforço de compreensão, isto é, de desvelamento da significação, do sentido, do valor dos objetos sobre os quais se volta (grifos nossos) (RIOS, 2006, p. 44).

É no cotidiano das aulas de Filosofia que os educandos vão descobrindo a dimensão intelectual do saber filosófico. Entretanto, a dificuldade de reconhecimento da Filosofia como prática educativa de um caráter questionador da realidade decorre de outra dificuldade que é a verticalidade das relações entre os sujeitos no contexto escolar. O receio de promoverem aulas que realizem debates filosóficos sobre assuntos que são vistos pela sociedade como tabus pode promover certo cuidado por parte de gestores e um consequente distanciamento da realidade por parte dos professores. Enquanto isso, na maioria das vezes, os debates passam por outros caminhos que não são os da análise crítica e significativa acerca dos problemas sociais e existenciais.

Diante dessas afirmações e comparações, queremos enfatizar que a realidade prática parece muitas vezes distante da teoria, uma vez que constantemente utiliza-se de termos distorcidos para legitimar a disciplina, o controle e a hierarquia. Nesse sentido, faz-se necessário conhecer a realidade de perto, ou seja, é preciso estar na escola, vivenciar o cotidiano de professores e alunos, para que assim, possamos modificar e transformar a prática docente em uma prática de qualidade.

O saber filosófico é um direito de todos, mas para garantir tal direito é preciso conhecê-lo. Não amamos ou gostamos do desconhecido. É necessário que a educação brasileira dê aos jovens o direito de filosofar, mas um filosofar repleto de conceitos e esclarecimentos sobre as condições do ser no seu devir.

Kant (1983) lembrava que não é possível ensinar a Filosofia, mas sim a filosofar. Assim, indagamos até que ponto os formadores dos futuros professores de Filosofia estão filosofando com os seus alunos estagiários sobre ser e estar educador no contexto social em que estão inseridos. Acreditamos que é no filosofar em sala de aula, na problematização das questões tratadas pela Filosofia, no direito à dúvida, nas perguntas que surgem em meio a debates em sala de aula sobre questões sociais, históricas que docentes e discentes tecem sua aprendizagem e sua identidade professoral.

Essa questão sobre ensino da Filosofia ou filosofar traz consigo o viés dialético, no sentido de que ao falarmos e discutirmos sobre Filosofia ou o seu ensino já estamos filosofando, debatendo, ou seja, estamos construindo um filosofar a respeito de algo, no caso em questão sobre o ensino de Filosofia. Sobre tal debate, Ghedin (2009, p. 57) afirma que filosofar pode ser compreendido como ato de retomada de dados disponíveis, na constante busca de significado: “É uma 
espécie de entrega interpretativa que teoriza a prática e pratica a teorização como possibilidade de compreensão e superação dos limites de nosso ser, lançado no horizonte de sentido".

O principal instrumento de conhecimento utilizado pela Filosofia da Educação é a prática docente. Contudo, nos questionamos quais as condições e possibilidades que viabilizam o exercício de uma prática docente de qualidade? Nessa direção, enfatizamos a prática, na tentativa de demonstrar o outro lado da Filosofia que não seja somente o teórico.

Por outro lado, é preciso que os licenciandos em Filosofia compreendam que o melhor filósofo não será necessariamente o bom professor de Filosofia, no sentido de que é fundamental que esse futuro professor tenha clareza da relevância do seu trabalho docente para o desenvolvimento educacional e social dos seus alunos, bem como conhecer o valor da prática procedente de uma teoria pautada na Filosofia da Educação.

Sabemos que o curso de licenciatura em Filosofia tem em seu projeto pedagógico o objetivo maior voltado para a formação do professor. Entretanto, há uma tendência ao que se chama "licenciatura com características de bacharelado". Visto dessa forma, o aluno prende-se à ideia de que o filósofo é somente um pensador e não um educador. No entanto, com a obrigatoriedade da Filosofia como disciplina do Ensino Médio e dos concursos públicos para tal fim, estes conceitos começam a ser repensados por alunos que pretendem ingressar na profissão docente na Educação Básica ou na universidade.

Contrapondo-se a essa ideia de filósofo da educação puramente teórico, Gallo (2007, p. 281) afirma que: “O filósofo da Educação, portanto, não é um filósofo qualquer, mas alguém, que habita o território educacional, que experimenta e vive seus problemas, e cria conceitos para enfrentá-los".

A Filosofia da Educação se constitui como um ramo do pensamento que se dedica a refletir acerca dos processos educativos, ou seja, direciona-se à análise dos sistemas educativos. Em suma, o processo reflexivo sobre a prática docente é fundamental para a compreensão da identidade do professor, pois observamos que cada vez mais essa identidade se fragmenta frente às transformações e reformas educacionais. Em consequência disso, a participação da Filosofia da Educação nos processos educativos está na tentativa de compreender as relações entre o fenômeno educação e as esferas da sociedade, bem como a relação entre ser existencial e ser social.

O plano normativo e prescritivo que rege o ensino-aprendizagem tem características complexas e marcantes, pois o ensinar está ligado a uma prática social repleta de propósitos e valores que envolvem todos os sujeitos que aceitam este desafio, buscando assim a sua autonomia intelectual dentro da docência, bem como a capacidade individual de criar e recriar ações educativas. 
Antes de falarmos na formação do professor de Filosofia é preciso que saibamos a importância da mesma no currículo escolar, ou seja, qual a justificativa da obrigatoriedade da disciplina no Ensino Médio. Contudo, sobre essa justificativa, Gallo comenta que:

Ora, nossos currículos de ensino médio são absolutamente científicos. Na mesma medida em que possibilitam o exercício dessa potência (quando o possibilitam, pois na maioria das vezes temos um ensino instrumentalizado e conteudista da ciência) acabam por desprezar as potências da arte e da filosofia. Penso que esta seja uma justificativa pertinente para a presença da filosofia nos currículos da educação média como expressão de um equilíbrio entre as potências da arte, da ciência, da filosofia, de modo que os jovens possam ter acesso a essas várias possibilidades de exercício do pensamento criativo, aprendendo a pensar por funções (ciência), mas também por perceptos e afectos (Arte) e por conceitos (Filosofia) (GALLO, 2007, p. 21).

Todavia, nos últimos anos, tem se intensificado as reflexões sobre a avaliação curricular, pois esta tem recebido críticas devido a sua natureza classificatória e excludente. As críticas, porém, têm sido acompanhadas de propostas que dizem respeito às mudanças nos currículos escolares e transformações no sistema avaliativo.

Diante disso, podemos dizer que o homem sempre busca a concretização de suas ações através de ações movidas pelo pensamento, pela necessidade de algo, pela ideia, e é nesse contexto que Marx afirma que:

Uma aranha executa operações semelhantes às do tecelão, e a abelha supera mais de um arquiteto ao construir sua colméia. Mas o que distingue o pior arquiteto da melhor abelha é que ele figura na mente sua construção antes de transformá-la em realidade. No fim do processo do trabalho aparece um resultado que existia antes idealmente na imaginação do trabalhador. Ele não transforma apenas o material sobre o qual opera; ele imprime ao material o projeto que tinha conscientemente em mira, o qual constitui a lei determinante do seu modo de operar e ao qual tem de subordinar sua vontade. E essa subordinação não é um ato fortuito. Além do esforço dos órgãos que trabalham, é mister a vontade adequada que se manifesta através da atenção durante todo o curso do trabalho. E isto é tanto mais necessário quanto menos se sinta o trabalhador atraído pelo 
conteúdo e pelo método de execução de sua tarefa, que lhe oferece por isso menos possibilidade de fluir da aplicação das suas próprias forças físicas e espirituais (MARX, 1985, p. 202).

Nesta passagem, Marx elabora de uma maneira primorosa a ideia de que o homem só consegue se realizar enquanto humano quando antecipa seus atos pelo pensamento. Ou seja, o homem precisa exteriorizar a sua subjetividade objetivamente. Assim, o homem produz uma cultura e uma história genuinamente humanas. Ou ainda, como diria Vásquez (1968), a objetivação aparece como uma necessidade para que o homem se realize e se autoproduza pelo trabalho e pela arte.

\section{O ensino de Filosofia como prática e como práxis}

Esse estudo está ancorado na perspectiva prática da Filosofia, no sentido de que esta é também reflexão-ação e não somente ação-reflexão, ou seja, o professor de Filosofia deve refletir sobre sua prática e como será essa prática dentro de uma imensidão de teorias e utopias filosóficas.

Tendo em vista o papel da teoria na consecução da prática, trouxemos para essa reflexão Pimenta e Lima (2004, p. 49), que comentam que a teoria tem o papel de oferecer aos professores diferentes perspectivas de análise e compreensão dos contextos (histórico, sociocultural, organizacional e do próprio sujeito) onde se desenvolve a atividade docente, com vistas à intervenção e à transformação. "Daí é fundamental o permanente exercício da crítica às condições materiais nas quais o ensino ocorre" (PIMENTA; LIMA, 2004, p.49).

Desse modo, entendemos que o homem é um ser que estabelece relações sociais com os demais e com a natureza. Nesse sentido, tais relações acontecem em meio a um processo prático do cotidiano, movido por ações imanentes do agir. É através do fazer que o homem vai construindo sua existência, como nos explica Severino (1994, p. 52) ao afirmar que o homem constrói e conserva sua existência na medida em que "[...] através de sua prática, vai se relacionando com a natureza, pelo trabalho, com a sociedade, pela sociabilidade, e consigo mesmo, pelo cultivo de sua subjetividade (grifos do autor)".

Entendemos que, se pusermos em prática esses três pontos, estaremos aptos ao exercício de uma prática produtiva e valorativa no que diz respeito às dimensões do trabalho e do universo das relações sociais. Todavia, atentamos 
na necessidade de pesquisar e estudar a prática do outro e a nossa, pois observar a prática docente quando se faz parte desta é como observar-se diante do espelho, olhar-se por inteiro, analisar-se minuciosamente, virar-se de um lado para o outro, pensar no que está bom no que deve ser mudado, e ao final desse ritual vaidoso não se dar por satisfeito e perante essa insatisfação tentar mudar o que lhe aflige, esteticamente falando. Assim deveria ser a observação crítica da própria prática: observar-se, analisar-se, e tentar mudar o que não está sendo conveniente nem para si e principalmente para o aprendizado do aluno. Não dá para fazer uma análise estética da prática, mas é preciso fazer uma análise crítico-reflexiva sobre os fins dessas ações educativas.

No plano da problemática aqui posta, voltemo-nos para a práxis. Em se tratando da relevância da práxis para os homens, Severino comenta que:

Pela sua práxis, os homens se tornam sujeitos, autores/agentes de sua própria história, em que pesem os comprometimentos de sua ação, decorrentes da resistência do mundo natural, da força opressora do social e da fragilidade da consciência subjetiva, lugares ambíguos onde ocorre também da despersonalização do humano, seja pela degradação do trabalho, pelas várias formas de dominação social e pela alienação ideologizante da cultura simbólica (SEVERINO, 1994, p. 149).

Portanto, aqui defendemos a relação do sujeito com a prática, mas não uma prática mecânica e reproduzida, mas sim uma prática efetiva e coletiva, que procura problematizar a educação.

Antes de falarmos sobre a ação docente referenciada na práxis, é necessário refletir sobre este conceito. Segundo Marx, citado em Pimenta (2006, p. 86), "práxis é uma atitude (teórico-prática) humana de transformação da natureza e da sociedade. Não basta conhecer e interpretar o mundo (teórico) é preciso transformá-lo (práxis)". A práxis se efetiva quando é fruto de uma ação consciente e transformadora, já a prática pode ser tida como ação mecânica, inconsciente e impulsionada. Entretanto, a teoria e a prática são fundamentais para chegarmos à práxis, pois a mesma é reflexão e ação consciente das duas.

A práxis, todavia, deve-se fazer presente na ação docente do professor de Filosofia, pois conforme Lipman (1995) há quatro pontos que transformam a prática comum em práxis crítica e em reflexão acima da ação: a primeira é a crítica da prática dos colegas; a segunda é a autocrítica; a terceira é a correção da prática dos outros e a quarta é a autocorreção.

Em se tratando dessas quatro etapas, só podemos modificar a prática reprodutora se fizermos da nossa prática um lugar de transformação e reflexão 
daquilo que já foi executado em sala de aula e assim lançarmos a autocorreção procedente da práxis.

No pensar filosófico, a práxis seria o ideal, pois a mesma é uma junção da teoria com a prática, porém uma junção refletida, pensada e transformada. Alguns estudiosos associam essa separação da teoria e da prática como algo negativo, que está ligada à identidade humana. Nessa perspectiva, Ghedin $(2009$, p. 79$)$ afirma que a teoria é indissociável da prática.

A separação destes significa arriscar perder a possibilidade da reflexão e da compreensão e, ainda, a negação da identidade humana. "Com efeito [...] ao se negar a indissociabilidade entre prática e teoria, nega-se aquilo que tornou o ser humano possível: a reflexão instaurada pela pergunta. A alienação encontra-se justamente na separação e dissociação entre os dois processos" (GHEDIN, 2009, p.79).

Acreditamos que o rompimento (teoria e prática) traz consigo o rompimento da identidade ontológica do ser com ele mesmo, ou seja, há uma negação do eu. Diante disso, defendemos a práxis na docência como ação filosófica que não separa, mas une a ação e a reflexão, sem desprezar os conhecimentos teóricos. Lima (2012, p. 28-29) alerta para o fato de que no momento em que reconhecemos o professor como intelectual em permanente construção e que tem o seu trabalho marcado pela vinculação direta ao conhecimento e pela compreensão da educação como um processo dialético de desenvolvimento do homem como ser historicamente situado "[...] entendemos, então que este profissional precisa da teoria para iluminar sua prática, e que esta precisa ser continuamente refletida para que sua teoria seja ressignificada".

$\mathrm{Na}$ relação dialética entre teoria e prática, construímos um filosofar que vai do subjetivo ao objetivo na busca do concreto e do espaço da Filosofia na docência. Nessa direção, fazemos um paralelo entre a práxis que se fundamenta como ação-reflexão-ação e do ensino proposto por Silvio Gallo, que se orienta em uma Filosofia problematizadora, que cria o problema em sala de aula (ação), pensa esse problema (reflexão) e resolve esse problema (ação).

Em se tratando do entendimento dialético e da prática como critério de verdade e condição existencial do homem, referendamos nossos estudos em Vieira Pinto (1979, p. 222) ao dizer que a prática só se constitui em critério de verdade quando é entendida como prática social: "A experiência existencial não oferece as condições para o estabelecimento do critério de verdade se o homem for concebido no isolamento da individualidade, desligado do correlacionamento, da inclusão no contexto coletivo". Sendo assim, só entendemos a prática como qualidade social quando compreendemos que esta é um dos pilares do saber docente. Além disso, ela interage com o saber filosófico, quando este sai do ideal para o real (prático), da reflexão-ação (teoria e prática), para ação-reflexão-ação (práxis). 


\section{As contribuições do Estágio Supervisionado na aprendizagem da profissão docente}

O Estágio Supervisionado é uma das disciplinas obrigatórias dos cursos de licenciaturas. Assim, tal experiência proporciona ao licenciando a oportunidade de vivenciar a realidade da sua futura profissão.

Por outro lado, esta observação da prática possibilita ao aluno estagiário a reflexão sobre a prática do outro, numa perspectiva crítico-filosófica. Além disso, esse momento é primordial para a observação das particularidades que compõem o cotidiano do trabalho docente que vai para além das estruturas físicas da escola. Como relata Lima (2012, p. 61): "É o olhar demorado sobre os fatos, nexos e relações que se estabelecem no movimento das pessoas para descobrir os fenômenos embutidos nos fatos aparentemente corriqueiros ou comuns as particularidades e detalhes do fenômeno estudado". O olhar a que se refere a autora é aquele que reconhece a escola como "organismo vivo, com identidade própria, construída pela comunidade que a compõe em sua especificidade e diferença das demais" (LIMA, 2012, p. 61).

Com efeito, muitas vezes esse momento perpassa diversas teorias pregadas em sala de aula acerca do magistério, pelo fato de estarmos observando não somente objetos, estruturas físicas e posturas profissionais dos professores de Filosofia, mas sim por se tratar de observar sujeitos em processo de formação e como esses sujeitos recebem esse conteúdo. O estágio é a hora de começarmos a pensar em nossas metodologias de ensino, utilizamos a palavra metodologia no plural com o intuito de ressaltar que o professor não deve utilizar apenas de uma só metodologia em suas aulas, pois se observa que muitos professores adotam apenas uma única metodologia para o ano inteiro.

Dessa forma, as aulas tornam-se desinteressantes para o aluno e o ensino de Filosofia mais desinteressante ainda. Trata-se de indagar qual o lugar do estágio na formação profissional. Severino (1994, p. 62) ressalta que por trás dessa indagação está a relação crítica entre a teoria e a prática, surgida de processos de ideologização que consideram a educação como "uma atividade intelectual autônoma". Tal concepção é historicamente problemática para aqueles que trabalham no campo da educação.

Ainda nessa linha de raciocínio, acreditamos no trabalho docente como um trabalho coletivo, conjunto, de professores e alunos. Portanto, o ensino de Filosofia, e mais especificamente o Estágio Supervisionado, acrescenta a ideia de que não se pode dar tratamento igual a desiguais, pois o ensinar enquanto atividade laboral e intelectual é em sua essência uma atividade temporal do aqui e 
agora, no sentido de que a aula de hoje jamais será igual à aula de amanhã, assim como as observações no estágio de hoje jamais serão as mesmas observações de amanhã, ou seja, a cada dia damos novos significados a novas observações e aprendizados.

Tomando-se o trabalho docente em seu sentido amplo, como produto de aprendizagem e atividade humana que estabelece vínculos com o coletivo, trouxemos para essa reflexão Tardif e Lessard (2007). Estes autores fazem observações acerca das indeterminações da docência, ao indicarem que o trabalho docente, considerando os seus resultados junto aos alunos, tem um alcance relativamente indeterminado, “[...] nenhum professor pode dizer que ele, sozinho, iniciou ou completou a educação de um aluno. Além disso, o trabalho docente é interdependente no tempo, é um trabalho coletivo de longa duração [...]" (TARDIF; LESSARD, 2007, p. 205).

Assim, concebemos a aproximação do filosofar com a docência, no sentido de que acreditamos no filosofar como acontecimento indeterminado e não no ensino que prevê o acontecido e o resultado da aprendizagem do aluno. Tal afirmação tem sua fundamentação nas palavras de Tardif e Lessard (2007) ao afirmarem a existência de outros fatores que contribuem para essa indeterminação, vinculados à complexidade dos contextos.

De certa maneira, às vezes torna-se difícil separar o trabalho e o produto desse trabalho. Entretanto, é preciso saber discernir a atividade intelectual, cuja finalidade é a aprendizagem e o conhecimento, do trabalho braçal que tem por objetivo a produção e o produto proveniente dessa produção e, por fim, a consumação de determinado produto. Contudo, para a indústria tudo isso deve acontecer no menor tempo possível, para que assim, produza-se mais e consumase cada vez mais. Dificilmente aplicaremos os objetivos de produção material no trabalho intelectual, pois este é um processo lento, contínuo e interminável, por se tratar da produção do homem para o próprio homem.

Em termos gerais, trata-se da construção e transformação do sujeito e não do objeto. Assim, nos permitimos ressaltar que o conhecimento e a aprendizagem cognitiva permitem ao homem a transição de seu estado de natureza ao estado de sociabilidade. Entretanto, os conhecimentos que tornam o estágio supervisionado um campo prático não estão restritos apenas à universidade, pois se encontram na sala de aula, onde o estagiário cumpre a disciplina da grade curricular do curso.

Compreendemos que o estágio é também um momento de decisão, no sentido de o aluno descobrir o ser professor, quais os limites e possibilidades da profissão, portanto, nessa ótica, Lima (2004, p. 16) afirma que: “O estágio não é a hora da prática! É a hora de começar a pensar na condição de professor na 
perspectiva de eterno aprendiz. É a hora de começar a vislumbrar a formação continua como elemento de realimentação dessa reflexão".

Enfim, essa etapa do curso que é o estágio contribui para uma possível construção da identidade e do saber docente do professor, numa perspectiva ontológica de descobrir-se professor. Em se tratando do saber pautado em bases ontológicas, Tonet (2005, p. 233) ressalta a exigência de um investimento redobrado "[...] Isso porque não se trata só de construir um saber - o que já exige sempre um grande esforço - mas de fazer a crítica do saber produzido na perspectiva dominante, em suas variadas formas $[\ldots]$ ".

Com as reflexões acima descritas, acreditamos que, gradualmente, os professores podem construir um saber de caráter emancipatório e ontologicamente fundado no processo de conhecimento efetivo que parte do particular para o universal. Acerca das possibilidades da concretização do aprendizado, Gallo (2008, p. 84) comenta a necessidade de se desconfiar da certeza de que tudo o que é ensinado é aprendido. Segundo o autor, desde os tempos bíblicos "[...] se falava que as sementes podem ou não germinar, dependendo do solo em que caem; pois bem: ensinar é como lançar sementes, que não sabemos se germinarão ou não; já aprender é incorporar a semente, fazê-la germinar, crescer e frutificar, produzindo o novo".

É preciso que o estagiário do curso de Filosofia compreenda o seu papel de educador e como tal, um de professor reflexivo, ou seja, aquele que também reflete sobre sua própria pratica. Importante se faz o reconhecimento da contribuição da perspectiva da reflexão no exercício do magistério para a valorização da profissão docente, dos saberes dos professores, do trabalho coletivo destes e das escolas, enquanto espaço de formação contínua. O professor pode produzir conhecimento a partir da sua prática, desde que na investigação reflita intencionalmente sobre ela, problematizando os resultados obtidos com o suporte da teoria. E, portanto, como pesquisador de sua própria prática (PIMENTA; GHEDIN, 2006).

O conhecimento da profissão é tão importante quanto o conhecimento da área específica do exercício do magistério, uma vez que o professor é um intelectual em processo contínuo de construção.

Para Ghedin (2009), a noção de conhecimento está ligada à própria existência do homem, porque o conhecimento nada mais é que nossa compreensão da realidade, que recebe repercussão do contexto cultural do qual fazemos parte. Dessa forma, a história do conhecimento se deu de diferentes maneiras, assim como ocorreu em lugares distintos, entre os quais a universidade. Neste processo de construção da ciência da forma que a conhecemos, estruturou-se sua base de sustentação. Nesse sentido, Ghedin nos diz que: 
Quanto ao conhecimento científico é necessário que ele seja constantemente questionado para responder as indagações que se faz a respeito da realidade, sendo para isso necessário processos investigativos sistemáticos de natureza explicativa e compreensiva, centrados em processos reflexivos mais do que em observações. Portanto, 'o conhecimento é resultante da relação que pode ser estabelecida entre experiência, interpretação e compreensão (GHEDIN, 2006, p. 166).

A Filosofia está, portanto, na base da tendência formativa e investigativa do professor reflexivo, uma vez que tais processos requerem do professor a interpretação e compreensão da realidade e estes necessitam do questionamento, da indagação e da problematização que a Filosofia pode favorecer.

\section{Resultados e discussão}

As discussões teóricas sobre o estágio na formação do professor de Filosofia fundamentaram a análise das falas dos alunos ${ }^{1}$ que passam pelo período de aprendizagem da profissão docente no curso de licenciatura. Ao serem indagados acerca do que compreendem por Estágio revelaram que suas percepções, se colocam em quatro direções: aprendizagem da profissão, conhecimento e compreensão da realidade, além da vivência da prática e observação da mesma.

\section{Aprendizagem da profissão}

Momento de preparação, aprendizagem por observação da prática (A1). É um periodo de aprendizado, do qual serve para adquirir experiências em um determinado meio, tornando o estagiário, conhecedor e capaz de desenvolver uma atividade até então nova ou desconhecida (A2). Momento de aprendizagem e de ouvir as exigências alheias (A3).

1 Expusemos os depoimentos dos dez licenciandos acerca do estágio, identificando-os pelas siglas A1, ..., A10. 
Importante verificar a preocupação dos alunos sobre a aprendizagem da profissão. Nesta mesma direção, Lima (2012) faz o detalhamento desse processo como: aprendizagem da hora da prática, aprendizagem da práxis docente e a aprendizagem do estágio como pesquisa. Verificamos também que um dos graduandos relatou que "[...] é o momento de ouvir as exigências alheias". Fica, portanto, evidenciado que há uma preocupação com o outro, com o aprendizado alheio.

\section{Compreensão da realidade}

Estágio para outra parte dos entrevistados lembra o conhecimento da realidade e a busca da compreensão da mesma. Dessa forma se expressaram os alunos:

O Estágio é o momento pelo qual nos leva a compreensão, sobre a importância das vantagens de ter conhecimento (A4).

Estágio significa a oportunidade de estar inserido dentro de um ambiente que lhe proporcione amadurecimento profissional, cultural e humano. No caso da sala de aula, ela proporciona a compreensão da realidade do processo de ensino- aprendizagem, a partir do contato direto com o professor e os alunos (A5).

Nessa perspectiva de compreensão da realidade enfatizada pelos investigados em questão, Ghedin (2009, p. 204) destaca que: “[...] à medida que vemos, trazemos para dentro tudo o que está fora. O olhar possibilita a passagem da subjetividade para a objetividade, criando inúmeras formas de ver os mesmos objetos".

Diante disso, tomemos o estágio por observação como o momento de observar a realidade na prática, ou seja, na maioria das vezes o que sabemos sobre o cotidiano escolar é proveniente de uma visão da realidade como apresentada nos livros e nas histórias de vida de professores e alunos. Entretanto, quando enxergamos a realidade através do olhar crítico-filosófico somos instigados a questionar o que está diante de nós, dessa forma somos levados a abstrair a realidade para transformá-la novamente em objetividade concreta. 


\section{Pôr em prática a teoria recebida}

Sobre a relação teoria e prática, três licenciandos comentaram sobre o que já é esperado pelos professores das disciplinas de estágio, que se constitui do seguinte ponto: pôr em prática o que foi aprendido na teoria, tal afirmação se evidência nas falas dos graduandos em destaque:

Para mim, o estágio é o momento de colocar em prática tudo o que foi aprendido de conhecimento na Academia (A6).

Estágio é o momento onde os alunos irão poder falar em prática o que já foi aprendido na teoria dentro das aulas de graduação (A7).

É uma oportunidade para conhecer a prática do conhecimento teórico (A8).

Nessa ótica, nos voltemos para as proposições práticas com vistas à práxis proposta por Lima (2004, p. 36), quando nos explica o movimento que se elucida na práxis: "Dentro do movimento: ação, reflexão e ação refletida é que a atividade docente é práxis".

Todavia, nos parece que o estágio assume esse papel de facilitador para sair da teoria e chegar-se à prática em seu sentido concreto. Contudo, não se pode deixar de enfatizar a necessidade da práxis na formação docente.

\section{Atitude de observação da profissão e da sala de aula}

Para finalizar os quatro itens que compuseram esse primeiro momento da análise das informações, faremos uma reflexão acerca das observações dos estagiários sobre o cotidiano escolar. Os licenciandos relataram o seguinte momento como sendo:

É uma oportunidade de observar e assumir um comportamento diante da futura profissão (A9).

É o momento que o aluno possui para se ter ideia do que seria o ensino em sala de aula (Aluno 10). 
Sobre esse momento de observar a prática e o espaço que a compõe, faremos um paralelo com a admiração, que é característica da atividade filosófica, pois esse admirar-se diante de algo ou alguém nos permite criar e recriar acontecimentos que facultam o pensar e o agir, ações estas que estão ligadas a dimensão estética do humano.

Em se tratando da admiração, Ghedin (2009, p. 43) afirma que: "A admiração é um olhar que se detém atenta e criteriosamente nas coisas, nos fenômenos e nos modos de interpretar e expressar a realidade". Para tanto, entendemos a observação como o momento do estágio que permite a ampliação do universo da realidade, pois quando apenas observamos o fenômeno sem que façamos parte dele, há uma maior probabilidade de formularmos o pensamento e a ideia pautados na imparcialidade e na veracidade daquilo que é observado.

\section{Considerações finais}

O contexto teórico e prático em que a pesquisa foi realizada nos possibilitou a concretização dos objetivos que compuseram nosso estudo, que consistia em analisar a compreensão dos alunos acerca do estágio no decorrer do curso de licenciatura. Para isso contamos com as pesquisa teórica e empírica efetivadas.

Concluir esta pesquisa significou um maior aprendizado sobre a profissão do filósofo educador e dos princípios que direcionam as atividades desenvolvidas nesta profissão, bem como o referencial teórico que serve de base para os estudos nesta área. Trata-se de um processo de construção identitária, que é capaz de superar e ressignificar as lacunas de formação acumuladas no decorrer do nosso processo formativo. A pesquisa, como parte da nossa formação, nos legitima na condição de intelectuais e abre espaço para novas buscas e investigações. Com estas reflexões chegamos aos principais achados da presente pesquisa:

- A análise dos dados nos leva a crer que a pesquisa em estágio apresenta a sistematização da prática docente e o valor dessa contribuição que vai para o estagiário, que a desvela na aprendizagem da profissão, na compreensão da realidade, na relação teoria e prática, na observação do cotidiano escolar, nas vivências de mundo. Essa conjuntura de aprendizagens contribui na construção da identidade docente;

- Os graduandos compreenderam o estágio de diversas maneiras, ou seja, para eles há uma multiplicidade de conceitos que definem as 
experiências vivenciadas no estágio, essa diversidade nos permitiu o enriquecimento avaliativo;

- Em decorrência das informações analisadas apontamos o estágio em Filosofia como o momento decisivo para a escolha da carreira docente. Portanto, é no cenário da escolar e na problemática das particularidades do cotidiano dos alunos que o graduando sai do mundo filosófico puramente subjetivo para o objetivo.

As reflexões que ficam dessa pesquisa, se estendem em três dimensões: a primeira, em relação à decantada política de valorização do magistério, que no tocante às Ciências Humanas são relegadas em favor das demais que estão ligadas ao mercado de concursos e ao aparato tecnológico. A segunda, relacionada aos cursos de licenciatura, que mantém as marcas do bacharelado em seu funcionamento, negando assim aos futuros professores de Filosofia o direito de se aproximarem da sua profissão e dos profissionais que a exercem, saindo destes cursos com carências formativas, que muitas vezes podem comprometer o seu desempenho profissional. A terceira dimensão centra-se na responsabilidade ética com a profissão docente e com o devido compromisso com o pensar filosófico-teórico e prático, diante dos acontecimentos que fazem parte do cotidiano dos alunos, da escola e do desempenho profissional.

\section{REFERÊNCIAS}

FLICK, Uwe. Introdução à pesquisa qualitativa. Tradução de Joice Elias Costa. 3. ed. Porto Alegre: Artmed, 2009.

GALLO, Silvio. Filosofia da Educação no Brasil do século XX: da crítica ao conceito. EccosRevista Cientifica. São Paulo, V. 09, n. 002, p. 261-284, Jul/Dez. 2007. Disponível em: http://www.scholar.google.com.br. Acesso em: 09 set. 2012.

GALLO, Silvio. A Filosofia e seu ensino: conceito e transversalidade. In: SILVEIRA, R. J. T; GOTO, R. Filosofia no Ensino Médio: Temas, problemas e propostas. São Paulo: Loyola, 2007.

GHEDIN, Evandro. Ensino de Filosofia no Ensino Médio. São Paulo: Cortez, 2009.

KANT, Immanuel. Crítica da Razão Pura. 2. ed. - São Paulo: Abril Cultural, 1983. Col. Os Pensadores.

LIMA, Maria S. L. Estágio e Aprendizagem da profissão docente. Brasília: Liber Livro, 2012. 
LIMA, Maria S. L. A Hora da Prática: reflexões sobre o Estágio Supervisionado e ação docente. 4. ed. - Fortaleza: Edições Demócrito Rocha, 2004.

LIPMAN, Matthew. O pensar na educação. Petrópolis: Vozes, 1995.

MARX, Karl. O capital: Crítica da economia política. São Paulo: Abril Cultural, 1985. Col. Os Pensadores.

PIMENTA, Selma Garrido. Estágio na Formação de Professores: Unidade Teoria e Prática?. 7. ed. - São Paulo: Cortez, 2006.

PIMENTA, Selma Garrido; GHEDIN, Evandro. Professor Reflexivo no Brasil: gênese e crítica de um conceito. Cortez Editora 2006

PIMENTA, Selma Garrido; LIMA, Maria Socorro Lucena. Estágio e Docência. São Paulo: Cortez, 2004.

PINTO, Álvaro Vieira. Ciência e existência: problemas filosóficos da pesquisa científica. 2. ed. - Rio de Janeiro: Paz e Terra, 1979.

RIOS, Terezinha A. Compreender e ensinar: por uma docência da melhor qualidade. 6 . ed. São Paulo: Cortez, 2006.

SEVERINO, Antônio Joaquim. Filosofia da Educação: Construindo a cidadania. São Paulo: FTD, 1994.

TARDIF, Maurice; LESSARD, Claude. O trabalho docente: elementos para uma teoria da docência como profissão de interações humanas. Petrópolis: Vozes, 2007.

TONET, Ivo. Educação, Cidadania e Emancipação Humana. Rio Grande do Sul: Unijuí, 2005.

VÁSQUEZ, Adolfo S. Filosofia da Práxis. Rio de Janeiro: Paz e Terra, 1968.

Texto recebido em 26/09/2019.

Texto aprovado em 24/02/2020. 